\title{
Effect of Tropical Climatic Conditions on the Stability of Cefaclor Dry Powder for Suspensions
}

\author{
BK Nanjwade $^{1 \star}$, M Shamrez Ali ${ }^{1}$, FV Manvi $^{1}$, MM Kanakal $^{2}$ \\ 'KLES's College of Pharmaceutical Sciences, K.L.E. University, Nehru Nagar, Belgaum Karnataka, India, \\ ${ }^{2}$ Department of Pharmaceutical Technology, School of Pharmaceutical Sciences, Universiti Sains Malaysia, 11800, \\ Pulau.Pinang, Malaysia
}

\begin{abstract}
Purpose: Two critical factors that govern the stability of pharmaceutical formulations in the tropics are humidity and temperature. This study was carried out to investigate the effect of moisture sorption at two different storage conditions on Cefaclor dry powder for oral suspension and predict the effect of moisture interaction on the reconstituted formulations

Method: Cefaclor dry powder for suspension formulation was taken as a model formulation for this study. Different formulations were manufactured and placed in twelve amber coloured glass bottles for each test condition. One set of bottles was sealed by heat induction technique under vacuum to ensure the integrity of the seal while the other set was without a seal but had a child-resistant cap. Both types of bottles were stored in humidity chambers at $30^{\circ} \mathrm{C} / 65 \% \mathrm{RH}$ or $40^{\circ} \mathrm{C} / 75 \% \mathrm{RH}$. Weight changes were monitored on a dynamic moisture balance over a period of 3 months.

Results: The results were recorded in terms of moisture content, colour, and excipient interaction and their effect on product appearance. The data were analyzed using Students t-test and one way analysis of variance (ANOVA), and differences were considered statistically significant at $P<0.05$.

Conclusions: The study revealed that the product with enhanced packaging and also contained nonwater soluble colourants were more protected against the deleterious effects of moisture and temperature. The findings provide an insight into a possible approach for formulating moisture-sensitive pharmaceutical products, especially dry powder preparations for use in the tropics.
\end{abstract}

Keywords: Dry powder for suspension; Moisture content; Colour; Stability; Moisture migration; Interaction. 


\section{INTRODUCTION}

Many solid pharmaceutical products may sorb moisture during long-term storage as commonly used packaging materials are permeable to moisture content. The moisture content of packaged products can be used as critical criterion for judging the quality of products that are degraded by moisture. In reality, however, this approach is expensive and extremely time-consuming. The ability to control and predict the moisture content during storage under a variety of conditions is very important for reducing the cost and cycle time of product development.

Container moisture permeability is a common ranking criterion used by pharmacopoeias [1]. However, permeability alone is not responsible for moisture uptake [2] since its rate is governed by environmental conditions and water activity in the container and within the components of a formulation. The rate of moisture permeation through a container usually decreases over time as humidity in the container increases due to accumulation of moisture in the container. Adsorption occurs with the water forming hydrogen bonds with the hydrophilic sites on the surface of the solid [3], and diffusional forces exceed the binding forces as more water molecules adhere to the surfaces and moisture is transferred into the material [4]. Consequently, moisture is adsorbed as mono- or multi-layer or may be present as normally condensed moisture. Multilayer water adsorption consists of water uptake into pores and capillary spaces, dissolution of solutes, and finally, the mechanical detention of water [5]. Water is adsorbed onto the surface of the pore wall at first and then is condensed and fills the core of the pore [6]. At high humidity, solid water-soluble particles at the surfaces begin to dissolve in adsorbed water vapour and form a saturated solution $[7,8]$.

Water in pharmaceutical products either as the residual water from processing or as the result of exposure to high relative humidity
$(\mathrm{RH})$ may affect the chemical or physical stability of moisture-sensitive products. Predictive approach may be used as a convenient tool for excipient selection and formulation design to protect moisturesensitive compounds, provided that there is no substantial polymorphic conversion during process [9].

This study was carried out to investigate the effect of moisture sorption at two different storage conditions on dry powder for oral suspension and predict the effect of moisture interaction on the reconstituted formulations in order to reduce the cost and cycle time of product development.

\section{EXPERIMENTAL}

\section{Materials}

Cefaclor monohydrate (Aurobindo Pharma, India), xanthan gum (Hem Industries, India), sodium benzoate (Thomas Baker, India), simethicone $30 \%$ emulsion (Waker, USA), simethicone powder (SPI Pharma, France), citric acid, anhydrous (DSM, India), Aerosil 200 (Evonik, India), FD\&C Red no. 40 lake, FD\&C Yellow no. 6 lake, FD\&C Red no. 40 dye and FD\&C Yellow no. 6 dye (all from Roha India), Tutti Frutti flavour powder and Orange flavour powder, (both from Givaudan, Switzerland), sodium lauryl sulphate (Cognis, Turkey), dried maize starch (National Starch, India), sodium saccharin (National Analytical Corporation, India), Caster sugar (Tetley, India), amber-coloured glass bottle (Gujrat Glass, India), child-resistant cap with hermatic seal (Nilkanth Caps, India), double cone blender (Yenchen, Taiwan), humidity and temperature controlled chambers(Thermolab, India), heat-induction sealer (Rikosys Code \& Pack Private Limited, India), weighing balance (model GC2502, Sartorius, AG Germany) and moisture balance (Sartorius, AG Germany), were used in this study.

Trop J Pharm Res, February 2010; 9 (1): 74 


\section{Preparation of dry powder suspension}

All the inactive ingredients were sifted through $600 \mu$ aperture sieve while the colours were separately sifted through $250 \mu$ before adding them to the other excipients to ensure homogeneity of colour throughout the mixture. It was then mixed for $10 \mathrm{~min}$ in a laboratory scale double cone blender. The mixture was then geometrically diluted with the active ingredient, cefaclor monohydrate to yield different formulations as outlined in Table 1. A quantity of the powder mixture (40g, accurately weighed) was placed in a $100 \mathrm{ml}$ amber-coloured glass bottle and capped with a child-resistant cap.

Table 1: Composition* of the four formulations (F1- F4) used in the study

\begin{tabular}{|c|c|c|c|c|}
\hline $\begin{array}{c}\text { Ingredient } \\
(\mathrm{mg} / 5 \mathrm{ml})\end{array}$ & F1 & F2 & F3 & F4 \\
\hline $\begin{array}{l}\text { Simethicone } \\
\text { powder } \\
(13.33)\end{array}$ & $\sqrt{ }$ & $\sqrt{ }$ & - & - \\
\hline $\begin{array}{l}\text { Simethicone } \\
30 \% \\
\text { emulsion (4.0) }\end{array}$ & - & - & $\sqrt{ }$ & $\sqrt{ }$ \\
\hline $\begin{array}{l}\text { FD\&C Red } \\
\text { no. } 40 \text { dye } \\
(0.08)\end{array}$ & $\sqrt{ }$ & - & $\sqrt{ }$ & - \\
\hline $\begin{array}{l}\text { FD\&C Yellow } \\
\text { no. } 6 \text { dye } \\
(0.05)\end{array}$ & $\sqrt{ }$ & - & $\sqrt{ }$ & - \\
\hline $\begin{array}{l}\text { FD\&C Red } \\
\text { no. } 40 \text { lake } \\
(0.8)\end{array}$ & - & $\sqrt{ }$ & - & $\sqrt{ }$ \\
\hline $\begin{array}{l}\text { FD\&C Yellow } \\
\text { no. } 6 \text { lake } \\
(0.8)\end{array}$ & - & $\sqrt{ }$ & - & $\sqrt{ }$ \\
\hline
\end{tabular}

*The following excipients $(\mathrm{mg})$ were also incorporated in each of the four formulations: Cefaclor monohydrate (266.54), xanthan gum (30.0), sodium benzoate (10.0), citric acid, anhydrous (10.0) Aerosil 200 (0.02), Tutti Frutti powder flavour (6.0), Orange flavour powder (6.0), sodium lauryl sulphate (0.5), dried maize starch (80.0), sodium saccharin (3.0), Caster sugar (1556.65).

\section{Moisture uptake determination}

Determination of moisture uptake of the formulations in the amber-coloured glass bottles was carried out at two different conditions. One set, containing 12 bottles of four different formulations, was sealed with a heat-induction sealer, and vacuum was used to ensure the integrity of the seal. The other set of bottles was not sealed but capped with child-resistant caps. Two sets of bottles for each formulation were stored in stability humidity chambers at $30{ }^{\circ} \mathrm{C} / 65 \% \mathrm{RH}$ and 40 ${ }^{\circ} \mathrm{C} / 75 \% \mathrm{RH}$, respectively. At weekly intervals, one bottle was withdrawn from the humidity chamber (for each storage condition) over a period of 12 weeks and moisture content (\%), colour change and excipient interaction were assessed.

\section{Determination of loss on drying}

An amount of powder content (2 g) taken from the bottle which was withdrawn from the humidity chamber at weekly intervals was subjected for the moisture content determination by placing the sample evenly distributed on an aluminum plate, prior to which the dynamic moisture balance was heated to remove any possible moisture present in an around the aluminum plate and the samples was heated at $105^{\circ} \mathrm{C}$ in order to determine the percentage content of the moisture pickup by the sample and the data in percentage was recorded.

Sodium chloride $(40 \mathrm{~g})$ was used as a reference/control, i.e., in place of cefaclor monohydrate, and subjected to the same tests as described above. The sodium chloride crystals were first powdered in a mortar with a pestle, passed through 600 micron and dried at $105{ }^{\circ} \mathrm{C}$ for $1 \mathrm{~h}$, in a wide mouth stainless steel container on a temperature controlled hot place to remove any adsorbed moisture and placed over calcium chloride desiccator before adding to 
the bottle. The bottles were also sealed/capped as described earlier.

\section{Statistical Analysis}

All statistical calculations were performed using the Statistical Package for Social Sciences (SPSS version $13.0^{\circledR}$ )software (Statistical Package for the Social Sciences) SPSS Inc.USA. Data were analysed using Student's t-test and one way analysis of variance (ANOVA), and differences were considered statistically significant at $P<0.05$.

\section{RESULTS}

\section{Effect of hermetic seal}

As Table 2 shows, the physical appearance of the powder mixtures in the bottles varied with the simulated climatic conditions and whether the bottles were hermetically sealed or not. Colour change of the mixture was slight when kept in hermetically sealed bottles; on the other hand, those in unsealed bottles showed pronounced colour change and segregated lumps were noticeably formed as well as sticking of the powder to the interior surface of the bottle, especially those stored at the higher temperature of 40 ${ }^{\circ} \mathrm{C}$.

\section{Effect of temperature and humidity}

Table 3 shows that the effect of temperature and humidity on the moisture content of the powder mixture varied significantly $(p<0.05)$ among some formulations but not in others, e.g., between F1 and F2 on the one hand, and F3 and F4 on the other. Furthermore, these parameters depended on test storage conditions.

\section{Reference/control}

The results for the reference/control (hygroscopic sodium chloride), which was used in place of cefaclor mixture (Table 2), indicate that there was a significant difference $(P<0.05)$ in moisture uptake between that which was hermetically sealed and the one that was not (fig. 1). The difference between the moisture uptake at $30{ }^{\circ} \mathrm{C} / 65 \% \mathrm{RH}$ and 40 ${ }^{\circ} \mathrm{C} / 75 \% \mathrm{RH}$ was also less pronounced for the reference than for cefaclor mixture.

Table 2: Appearance of powder formulations over a storage period of 12 weeks under various conditions

\begin{tabular}{|c|c|c|c|c|c|}
\hline & & \multicolumn{4}{|c|}{ Appearance } \\
\hline & & $\begin{array}{c}1^{\text {st }} \\
\text { week }\end{array}$ & $\begin{array}{c}4^{\text {th }} \\
\text { week }\end{array}$ & $\begin{array}{c}8^{\text {th }} \\
\text { week }\end{array}$ & $\begin{array}{c}12^{\text {th }} \\
\text { week }\end{array}$ \\
\hline \multirow{4}{*}{ A } & $\mathrm{F} 1$ & * & * & $* * *$ & $* * *$ \\
\hline & $\mathrm{F} 2$ & * & * & $* \star$ & $* * *$ \\
\hline & F3 & * & $\star *$ & $\star \star *$ & $\star * * *$ \\
\hline & $\mathrm{F} 4$ & * & * & ** & $* * *$ \\
\hline \multirow{4}{*}{ B } & $\mathrm{F} 1$ & * & * & * & ** \\
\hline & $\mathrm{F} 2$ & * & * & * & * \\
\hline & F3 & * & * & ** & ** \\
\hline & $\mathrm{F} 4$ & * & * & * & ** \\
\hline \multirow{4}{*}{ C } & $\mathrm{F} 1$ & $* *$ & $* * *$ & $* \star \star *$ & $* * * *$ \\
\hline & $\mathrm{F} 2$ & * & ** & ** & $* * *$ \\
\hline & F3 & $* *$ & $\star * *$ & $* * * *$ & $* * * *$ \\
\hline & $\mathrm{F} 4$ & ** & $* *$ & $* * *$ & $* * * *$ \\
\hline \multirow{4}{*}{ D } & $\mathrm{F} 1$ & * & * & * & ** \\
\hline & $\mathrm{F} 2$ & * & * & * & ** \\
\hline & F3 & $*$ & * & $* *$ & $\star * *$ \\
\hline & $\mathrm{F} 4$ & * & * & * & $* * *$ \\
\hline
\end{tabular}

$\mathbf{A}=30^{\circ} \mathrm{C} / 65 \% \mathrm{RH}$ without hermetic seal; $\mathbf{B}=30$ ${ }^{\circ} \mathrm{C} / 65 \% \mathrm{RH}$ with hermetic seal; $\mathrm{C}=40{ }^{\circ} \mathrm{C} / 75 \% \mathrm{RH}$ without hermetic seal; $\mathbf{D}=40{ }^{\circ} \mathrm{C} / 75 \% \mathrm{RH}$ with hermetic seal.

Note: *No physical change; ${ }^{* *}$ slight change in colour; ${ }^{* * *}$ marked colour change; ${ }^{* * * *}$ Segregated lump formed with distinct colour. 
Table 3: Mean moisture content of powder formulations over a storage period of 12 weeks under various conditions: $\mathbf{A}=30{ }^{\circ} \mathrm{C} / 65$ $\% \mathrm{RH}$ without hermetic seal; $\mathbf{B}=30{ }^{\circ} \mathrm{C} / 65$ $\% \mathrm{RH}$ with hermetic seal; $\mathbf{C}=40{ }^{\circ} \mathrm{C} / 75 \% \mathrm{RH}$ without hermetic seal; D $=40{ }^{\circ} \mathrm{C} / 75 \% \mathrm{RH}$ with hermetic seal (Note: Codes F1 - F4 are as indicated in Table 1).

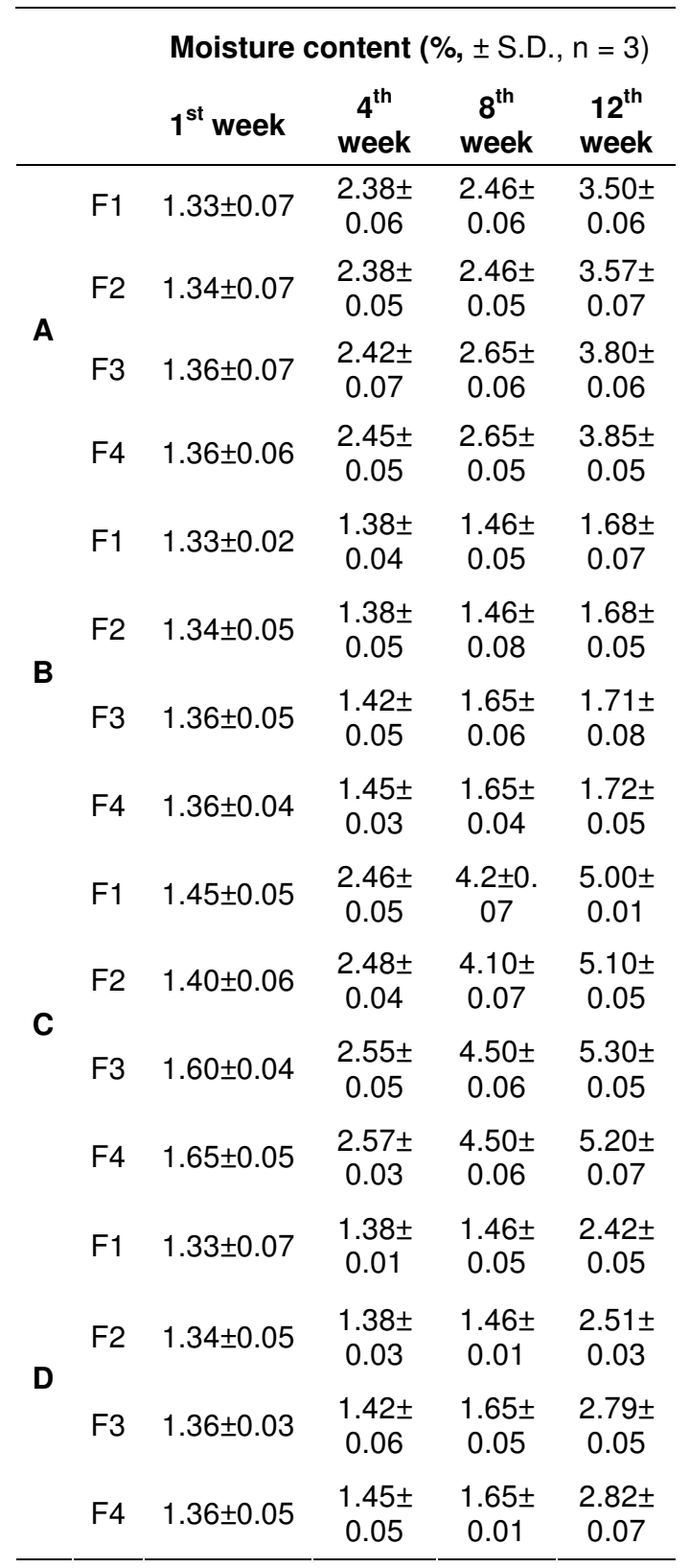

$\mathbf{A}=30^{\circ} \mathrm{C} / 65 \% \mathrm{RH}$ without hermetic seal; $\mathbf{B}=$ $30^{\circ} \mathrm{C} / 65 \% \mathrm{RH}$ with hermetic seal; $\mathbf{C}=40^{\circ} \mathrm{C} / 75 \%$ $\mathrm{RH}$ without hermetic seal; $\mathrm{D}=40^{\circ} \mathrm{C} / 75 \% \mathrm{RH}$ with hermetic seal. (Note: $\mathrm{F} 1=\mathbf{\square} ; \mathrm{F} 2=\Delta ; \mathrm{F} 3=\square ; \mathrm{F} 4=$ $\diamond)$.

\section{DISCUSSION}

\section{Effect of colouring agent}

Water molecules first adsorb onto the surface of a dry material to form a monomolecular layer which is subjected to both surface binding and diffusion forces. Diffusion forces exceed binding forces as more water molecules adhere to the surface and moisture is transferred into the interior of the material. Thus, moisture is adsorbed as mono- or multi-layer or may be present as condensed moisture [4].

The aim was to study the effect of the different types of colouring agents on the physical stability of the powder formulations; hence, the powders were designed to incorporate interacting options in order to gain insight into the appearance of the powders as indicated in Table 2. For freshly prepared formulations $\mathrm{F} 1$ and $\mathrm{F} 3$ (containing water soluble colourants), the appearance was influenced by the colour of both the active ingredient and excipients while for F2 and F4 (which contain aluminum lake colourant), the colour was generated by the aluminum lake. It is clear that the formulations $\mathrm{F} 1$ and $\mathrm{F} 3$ showed distinct change in colour during storage compared with F2 and F4 under similar storage conditions. The change in colour may be due to the fact that water-soluble colours are more readily soluble in little amount of water than dye lakes. This suggests possible interaction of the colourants with water within the excipients which equilibrates with the head space moisture of the bottle as temperature increases. Interaction with colourant would occur during migration of moisture from excipients towards the headspace of the bottle. 

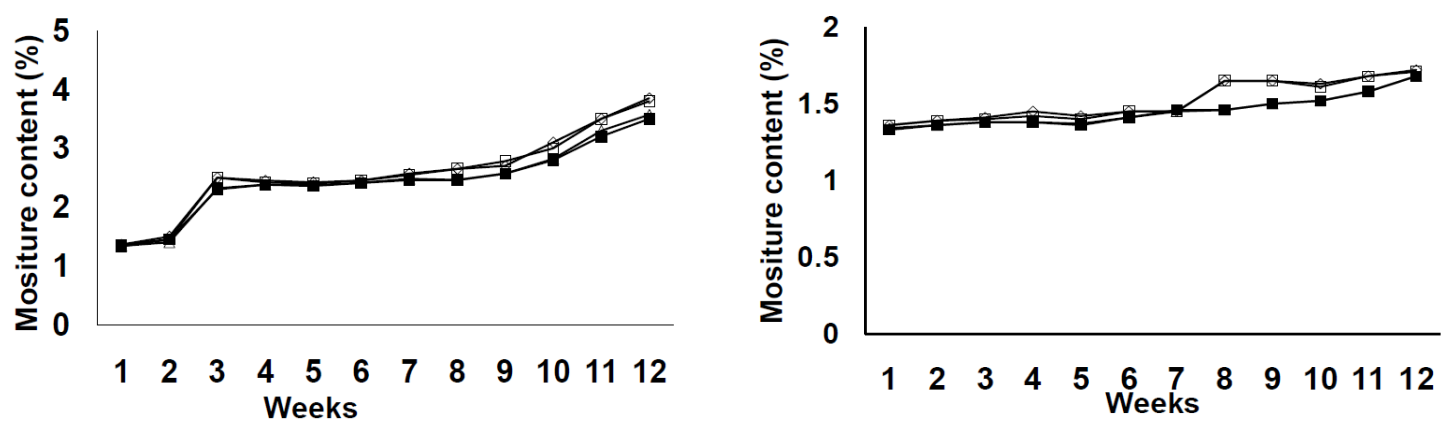

[C]

[D]
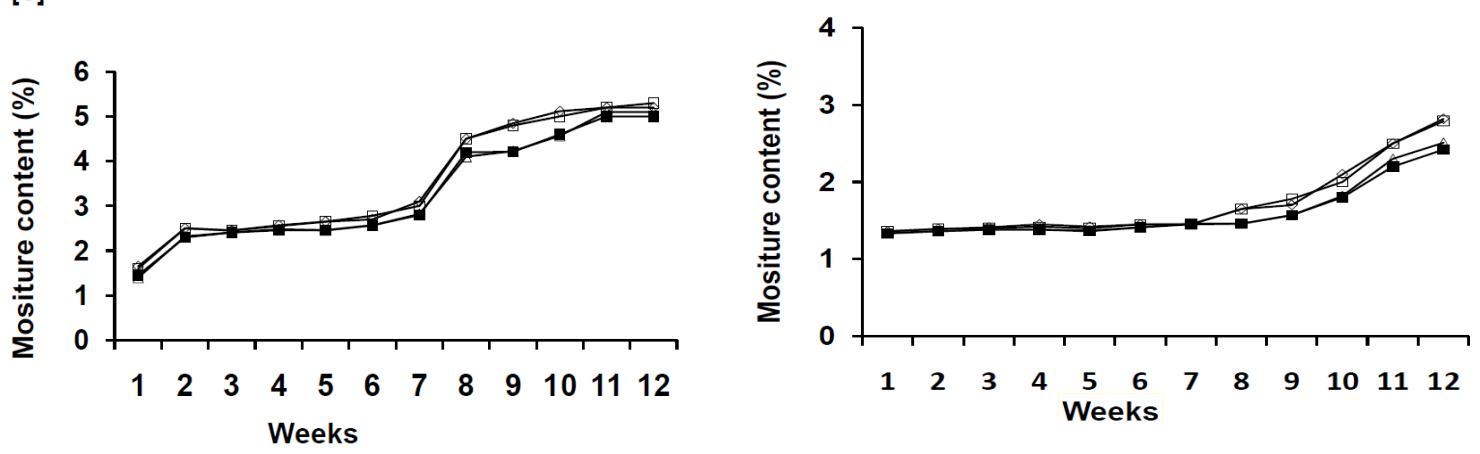

Fig 1: Moisture uptake by powder formulations over a storage period of 12 weeks under various conditions: $\mathbf{A}=30^{\circ} \mathrm{C} / 65 \% \mathrm{RH}$ without hermetic seal; $\mathbf{B}=30^{\circ} \mathrm{C} / 65 \% \mathrm{RH}$ with hermetic seal; $\mathbf{C}=40^{\circ} \mathrm{C} / 75 \% \mathrm{RH}$ without hermetic seal; $\mathbf{D}=40^{\circ} \mathrm{C} / 75 \% \mathrm{RH}$ with hermetic seal. (Note: $\mathrm{F} 1=\mathbf{a} ; \mathrm{F} 2=\Delta ; \mathrm{F} 3=\square ; \mathrm{F} 4=\diamond$ ).

Equilibrium moisture sorption properties of a product is a key factor affecting the rate of moisture uptake by a packaged product during its shelf life, in addition to environmental conditions and container permeability $[8,11]$. Water-soluble colourants tend to dissolve in adsorbed moisture, either from the atmosphere or from the excipients when temperature conditions are elevated, thus producing a segregated mottled lump with a definite colour change.

\section{Interaction between emulsion and colour}

Some anti-foaming agents are used to reduce the excess foam generated by wetting agents, and in this regard, they are traditionally used as emulsions, being processed along with the excipients during the manufacturing process. However, it is difficult to dry them completely and take out most of the water from the emulsions, which is one of the reasons why lumps are generated during the shelf life of a product.

Formulation F3, which contains a watersoluble colour as well as antifoaming agent (simethicone $30 \%$ emulsion), showed greater interaction (compared to the other formulations) with water as indicated by intense colour change and formation of segregated lumps when the powder formulation was stored without hermetic seal under the two test storage conditions used. The fact the formulations (F1 and F2) which contained simethicone powder, instead of simethicone $30 \%$ emulsion, showed a more stable behaviour, i.e., less pronounced colour change, indicates that the moisture level of 
the formulations exerted an influence on product stability.

\section{Most suitable Cefaclor powder composition}

The most suitable formulation, of all those evaluated, was F2 (see Table 1). This formulation, which contained a water insoluble colouring agent, resisted dissolution of the colourant in the sorbed water. Another factor was that simethicone powder has no free water in it. Consequently, it would be less prone to forming segregated lumps in the suspension. Thus, the most suitable cefaclor formulation should, ideally, contain a non-water soluble colouring component and a dry antifoaming agent.

\section{CONCLUSION}

The interaction of moisture with pharmaceutical solids plays an important role in the formulation of solid dosage forms, especially powder formulations. Formulations that contain water-soluble colouring agents, as opposed to aluminum lake colours (which are water-insoluble), together with excipients that have no unbound water, would cause a mottling effect, thus resulting in the failure of the product to satisfy specifications for physical appearance. This study has also demonstrated that a reliable container with minimal permeability and which is hernetically sealed is necessary to protect dry powder pharmaceutical products. In spite of some limitations, excipient moisture sorption data should be useful in predicting solid-state stability, interactions, as well as the effect of moisture on the physicochemical behaviour of the final product.

\section{ACKNOWLEDGEMENT}

The authors would like to thank Mr Krishna Prasad and Aurobindo Pharma, for providing cefaclor free of charge, and also Mr Ramesh Venkatraman of Pharmatest, India and Middle East, for making their facility available for the cross-verification of the data obtained.

\section{REFERENCES}

1. United States Pharmacopeia 30/National Formulary; USP Convention Inc., Rockville, MD, USA, 2007; monograph 671.

2. Badawy SIF, Gawronski AJ. Application of sorptiondesorption moisture transfer modeling to the study of chemical stability of a moisture sensitive drug product in different packaging configurations. Int. J. Pharm, 2001; 223: 1-13.

3. Brittain HG. Overview of physical characterization methodology. In Physical characterization of pharmaceutical solids, Brittain HG, Ed, New York, USA, Marcel Dekker Inc., 1995, pp. 135.

4. York P. Analysis of moisture sorption hysteresis in hard gelatin capsules, maize starch, and maize starch: drug powder mixtures. J Pharm Pharmacol, 1981; 33: 269-273.

5. Barbosa-Cánovas GV, Vega-Mercado H. Physical, chemical, and microbiological characteristics of dehydrated foods. In: Dehydration of foods, Barbosa-Cánovas GV, Vega-Mercado $H$, Eds., New York, USA, Chapman \& Hall, International Thompson Publishing, 1996, pp. 29-99.

6. Aharoni C. The solid-liquid interface in capillary condensation. Sorption of water by active carbons. Langmuir, 1997; 13: 1270-1273

7. Van Campen L, Amidon GL, Zografi G. Moisture sorption kinetics for water-soluble substances I: Theoretical considerations of heat transport control. J Pharm Sci, 1983; 72: 1381-1388.

8. Kontny MJ, Zografi G. Sorption of water by solids: In: Physical characterization of pharmaceutical solids Brittain HG Ed, New York, USA , Marcel Dekker Inc., 1995, pp 387-418.

9. Yanxia L, Yeshwant D. Sanzgiri, Yisheng CA. Study on Moisture Isotherms of Formulations: the Use of Polynomial Equa-tions to Predict the Moisture Isotherms of Tablet Products. AAPS PharmSciTech, 2003; 4: (4) article 59.

10. Zografi G, Grandofi GP, Kontny, MJ, Mendenhall DW. Prediction of moisture transfer in mixtures of solids: transfer via the vapor phase. Int. J. Pharm., 1988; 42: 77-88.

11. Kontny MJ, Koppenol S, Graham ET. Use of the sorption-desorption moisture transfer model to assess the utility of a desiccant in a solid product. Int. J. Pharm, 1992; 84: 261-271. 